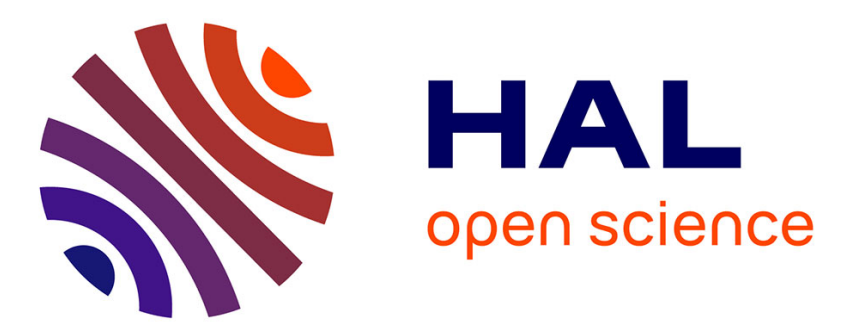

\title{
Crystal Structure of A-amylose: a Revisit from Synchrotron Microdiffraction Analysis of Single Crystals
}

D. Popov, A. Buléon, M. Burghammer, H. Chanzy, N. Montesanti, J.-L.

Putaux, G. Potocki-Véronèse, C. Riekel

\section{- To cite this version:}

D. Popov, A. Buléon, M. Burghammer, H. Chanzy, N. Montesanti, et al.. Crystal Structure of Aamylose: a Revisit from Synchrotron Microdiffraction Analysis of Single Crystals. Macromolecules, 2009, 42 (4), pp.1167-1174. 10.1021/ma801789j . hal-00353934

\section{HAL Id: hal-00353934 \\ https://hal.science/hal-00353934}

Submitted on 16 Jan 2009

HAL is a multi-disciplinary open access archive for the deposit and dissemination of scientific research documents, whether they are published or not. The documents may come from teaching and research institutions in France or abroad, or from public or private research centers.
L'archive ouverte pluridisciplinaire HAL, est destinée au dépôt et à la diffusion de documents scientifiques de niveau recherche, publiés ou non, émanant des établissements d'enseignement et de recherche français ou étrangers, des laboratoires publics ou privés. 
Crystal Structure of A-amylose: a Revisit from Synchrotron Microdiffraction Analysis of Single Crystals

D. Popov*`, A. Buléon ${ }^{\ddagger}$, M. Burghammer ${ }^{\dagger}$, H. Chanzy ${ }^{\S}$, N. Montesanti ${ }^{\S}$, J-L. Putaux ${ }^{\S}$, G. Potocki-Véronèse ${ }^{\pi}$, C. Riekel ${ }^{\dagger}$

${ }^{\dagger}$ European Synchrotron Radiation Facility, BP 220, F-30843, Grenoble Cedex, France;

${ }^{\ddagger}$ INRA, Rue de la Géraudière, BP 71627, 44316, Nantes Cedex 3, France; ${ }^{\S}$ Centre de Recherches sur les Macromolécules Végétales (CERMAV-CNRS), BP 53, F-38041 Grenoble Cedex 9, France - affiliated with the Joseph Fourier University and member of the Institut de Chimie Moléculaire de Grenoble; "Laboratoire d'Ingénierie des Systèmes Biologiques et des Procédés (LISBP), UMR 5504 INSA-CNRS, UMR 792 INSA-INRA, 135 Avenue de Rangueil, F-31077 Toulouse Cedex 4, France.

*corresponding author. 


\section{Abstract}

The three-dimensional structure of A-amylose crystals, as a model of the crystal domains of A-starch granules, was revised using synchrotron radiation microdiffraction data collected from individual micron-sized single crystals. The resulting datasets allowed a determination of the structure with conventional X-ray structure determination techniques normally used for small molecules and not for polymers. Whereas the gross features of this improved structure do not differ extensively from previous structure determination, the high resolution of the diffraction diagrams, which is unusual for a crystalline polymer, allowed the resolution of important new fine details. These include a distortion of the amylose double helices resulting from the occurrence of two intracrystalline molecules of water and a tight network of hydrogen bonds involving each of the primary and secondary hydroxyl groups of the glucosyl moieties. Pairs of water molecules are located in discrete pockets that do not interfere with one another. In addition, the refinement of the new structure indicates a "parallel-down" organization of the amylose molecules within the unit cell as opposed to the previous "parallel-up" model. This new feature indicates that within the crystals, the nonreducing ends of the amylose molecules are oriented toward the $c$-axis direction of the unit cell. The description of this geometry is important to correlate the crystallography of the granules of A-starch with their ultrastructure and their mode of biosynthesis.

Here, we present for the first time the resolution of the structure of a polymer crystal from a full X-ray dataset collected on micron-sized polymer single crystals using synchrotron radiation microdiffraction. This achievement is a substantial advance, which opens the way to many more studies since the technique of growing polymer and biopolymer single crystals is well established. 


\section{Introduction}

As opposed to the molecular and crystal structure determination of low molecular weight compounds, which is being done with great precision on a routine basis, the resolution of the structure of polymer crystals is still a major challenge since it requires a number of intuitive guesses together with trial-and-error methods. ${ }^{1}$ Indeed, many small molecules are susceptible to be crystallized as millimeter or sub-millimeter-sized crystals, yielding extensive diffraction datasets, with frequently more than 10 to 20 observed reflections per independent atom, the minimum ratio that is required for a proper structure refinement. ${ }^{2}$ This is not the case for most polymers for which only crystals with dimensions ranging from sub-micron to the micron can be obtained. These crystals are far too small to yield substantial X-ray datasets when conventional X-ray diffractometers are used. In most cases, one relies on the study of crystalline fibers, in which a large number of extremely small polymer crystals are aligned with their chain axis lying along the fiber direction, but distributed in a more or less cylindrical organization perpendicular to the fiber axis. With a few exceptions, the resulting fiber diffraction diagrams are limited in resolution. Furthermore, their deconvolution into a three dimensional data set is frequently a major challenge that is not always easy to overcome unambiguously. Even simple crystallographic parameters such as those of the unit cell or the space group and symmetry elements are difficult to deduce from X-ray fiber diffraction diagrams of polymers.

In view of their small size, isolated polymer single crystals are usually amenable to electron diffraction analysis, ${ }^{3}$ provided that the electron beam intensity is kept low and that the vacuum of the transmission electron microscope does not damage the crystals. In the best cases, a series of meaningful spot electron diffraction diagrams can be recorded from individual polymer crystals. These electron diffraction diagrams, which frequently are of high resolution, have become quite useful to ascertain the unit cell parameters and symmetry elements of the crystal systems of many polymers. ${ }^{4}$ In particular, electron diffraction analysis 
can be of great help to deconvolute the fiber X-ray diagrams and in a number of cases, the input of electron diffraction has corrected erroneous unit cells and symmetry elements that had been proposed earlier from X-ray fiber diffraction analysis. Despite these advances, the exploitation of the electron diffraction intensities for crystal structure determination is not straightforward, since one needs to subtract dynamic contributions from electron diffraction intensities before any further analysis. At present, there is no satisfactory way to measure or calculate this dynamic contribution for polymer crystals.

The resolution of the crystal structure of A-amylose is the focus of this report. Amylose, the linear constituent of starch can be recrystallized in vitro into the A or B allomorphs that are present in various native starches. The low crystallinity and complex ultrastructure of the starch granule do not allow a direct determination of the three-dimensional shape and distribution of the crystalline domains. Thus, structural models established from A- or B-amylose crystals can be transposed to the crystalline regions of native starch, which exhibit similar, but much less resolved diffraction diagrams. Getting an accurate molecular description of the A allomorph is important, since it is one of the main constituents of A-starch, ${ }^{5}$ chiefly found in cereal starch, which not only constitutes an essential food product for humankind, but also serves as a base for a number of non-food industrial uses.

Whereas the first X-ray powder diagrams of A-amylose had already been recorded in $1930,{ }^{6}$ it is only in the late seventies that a first three-dimensional model was proposed by the group of Sarko, using X-ray fiber diffraction diagrams showing 46 measurable diffraction spots. ${ }^{7}$ At that time, it was proposed that A-amylose was crystallized as parallel stranded, right-handed double helices, organized in an orthorhombic unit cell, with unspecified space group. In addition, the model showed that the double helices were packed in an antiparallel fashion. Thanks to the successful preparation of micron-sized A-amylose single crystals ${ }^{8}$ and their study by electron diffraction, ${ }^{9}$ the X-ray fiber diffraction diagrams of Sarko could be re- 
indexed. A new unit cell was derived and the monoclinic space group B2, indicative of highly symmetrical structure, was proposed. Using the 34 strongest intensities of the dataset of Sarko's group, together with the electron diffraction information, an improved structure of Aamylose was proposed by Imberty et al., combining conformational analysis and X-ray refinement. ${ }^{10}$ This new A-amylose model was still made of parallel-stranded double helices, but they were left-handed instead of the previous right-handed ones. In addition, these double helices were packed in a parallel fashion as opposed to Sarko's structure, where the packing was antiparallel. In view of the unit cell and symmetry elements, the structure proposed by Imberty et al. was described as resulting from an independent maltotriosyl residue, which was positioned in a parallel-up ${ }^{11}$ mode within the unit cell and there was one water molecule per trisaccharide unit. ${ }^{10}$ Despite its novelty, this model could not be refined, since the three dimensional coordinates of the 34 independent non-hydrogen atoms of this amylose hydrate could not be localized with precision, using only 34 diffraction intensities, each of them consisting of a number of overlapping reflections.

The recent development of microfocus beamlines at $3^{\text {rd }}$ generation synchrotron radiation sources, such as the ESRF in Grenoble, ${ }^{12}$ has drastically changed the situation, as novel X-ray optical systems, allowing the production of focal spots with diameters in the micron and sub-micron sizes are now available. In addition, goniometers for keeping a single crystal in the center of micron-sized beams have also been developed. ${ }^{13,14}$ Thus, when applied to very small crystalline objects such as a polymer single crystal, one can envisage the recording of X-ray datasets more complete than those recorded in electron diffraction experiments, and therefore susceptible to yield improved structural models. This paper follows a preliminary report, which showed that spot X-ray diagrams could be recorded on 5-10 $\mu \mathrm{m}$ needle-like single crystals of A-amylose, using a synchrotron X-ray beam of $10 \mu \mathrm{m} .{ }^{15}$ Here, we show how a full three-dimensional dataset was collected on such microcrystals and used to refine the structure of this amylose allomorph. To our knowledge, 
this is the first polymer structure determined using this technique on such small polymer single crystals. Getting an accurate atomic description of the A-amylose crystal is important since these crystals constitute part of the cereal starches, a food product of capital importance.

\section{Experimental}

Sample preparation. Amylose was enzymatically synthesized in vitro by amylosucrase ${ }^{16}$ from sucrose as glucosyl donor and maltose as acceptor, using a molar ratio of 6 . The reaction products were subsequently fractionated by preparative gel filtration, using a 7 L column of Biogel P-2 Fine (Biorad), and freeze-dried for further use. A fraction of amylose with an average degree of polymerization (DPn) of 17 and a polydispersity of 1.06 was used to prepare single crystals of A-amylose by recrystallizing dilute aqueous amylose solutions in presence of acetone vapors, as described elsewhere. ${ }^{9}$ Typical needle-shaped crystals are shown in Figure 1a. Using a Kleindiek MM3A micromanipulator under an optical microscope, individual crystals were glued with Araldite ${ }^{\circledR}$ to the tip of a tapered glass capillary (Figure 1b). The orientation of the needles with respect to the glass capillary varied from almost parallel to almost perpendicular.

Data collection. Experiments were performed at the ID13 beamline of the European Synchrotron Radiation Facility (Grenoble, France), with a wavelength of $\lambda=0.9465 \AA$ defined by a Si-111 monochromator. The beam was focused with parabolic Be-refractive lenses ${ }^{17}$ and collimated to either 10 or $30 \mu \mathrm{m}$ at the ID13 microgoniometer, ${ }^{18}$ operating with a flux of $10^{11}$ photons/s. The crystals were flash-frozen to $100 \mathrm{~K}$ using a $\mathrm{N}_{2}$ cryostream system. Diffraction patterns were recorded on a MAR165 CCD with $2 \mathrm{~K} \times 2 \mathrm{~K}$ pixels of $78.94 \times 78.94 \mu \mathrm{m}^{2}$ and 16 bit readout. Individual patterns, such as the one exemplified in Figure 2, were obtained on crystals that were rotated by 2 to $4^{\circ}$ during data collection, with exposure times of 1 to $2 \mathrm{~s}$. The diffraction patterns were processed using the XDS package. ${ }^{19}$ As was reported before, ${ }^{15}$ 
severe radiation damage strongly reduced the number of patterns that could be collected on one crystal, because of structural decay and concomitant drop of the spot intensities. For this reason, and in order to increase redundancy and completeness of the diffraction information, datasets collected on 14 different crystals having 10-15 $\mu \mathrm{m}$ length and 2-3 $\mu \mathrm{m}$ thickness were merged using the XSCALE software. ${ }^{19}$ The X-ray data sets were collected in 20-30 s of total exposure which corresponds to a change of unit cell parameters introduced by the radiation damage of about $0.1 \AA .{ }^{15}$ A summary of the experimental parameters is given in Table 1 . The compatibility of the collected data sets was checked by verifying that the correlation coefficients between the intensity values in each dataset were reasonably high. It was found that the dataset collected on a given crystal could be merged with at least 4 others with a correlation coefficients higher than 0.95 . With a few other crystals, selected correlation coefficients deviated below this limit but were never smaller than 0.8 . Typical $I / \sigma$ value estimated at the stage of integration of the diffraction images were not higher than the final $\mathrm{I} / \sigma$ value obtained after the scaling of all the intensity data. The final value of the $\mathrm{R}_{\mathrm{mrgd}-\mathrm{F}}=0.137$ which reflects the quality of the intensity data in terms of statistics was significantly lower than $\mathrm{R}_{\text {sym }}=0.193$.

Data reduction and structure refinement. Previous results of data reduction ${ }^{15}$ have confirmed the B2 space group already proposed by Imberty et al. ${ }^{9}$ Data collected on four crystals showing the smallest structural change introduced by the radiation damage was used to refine the unit cell parameters: $a=20.83(6) \AA, b=11.45(4) \AA, c=10.58(3) \AA, \gamma=122.0(2)^{\circ}$. The crystal structure was solved using a molecule replacement technique with the PATSEE software $^{20}$ within the WinGX program complex. ${ }^{21}$ A fragment of a regular left-handed 6-fold helix ${ }^{10,22}$ of 3 residues length without primary hydroxyl groups was used as a search fragment. A reasonable orientation was found for the search fragment with respect to 2-fold symmetry axis giving infinite double helix. The model was refined using SHELXL. ${ }^{23}$ The positions of primary hydroxyl groups and two positions of water molecules were found on 
electron difference maps. At the beginning of the refinement, a rigid group approach was used and then bond length, angular and anti collision restraints were applied. Pyranose hydrogen atoms were inserted into calculated positions and included into refinement in the 'riding' model whereas the hydrogen atoms of the hydroxyl groups were not considered. During all the refinement, occupations of water molecules were fixed at 1 but after the final stage, they were refined starting from 0.5 and 1 with either fixed or unfixed thermal parameters of water molecules. In these four cases, the final value did not deviate from 1 by more than the estimated standard deviation (e.s.d.). The final refinement, which was done in the isotropic approach of thermal parameters, gave $\mathrm{R} 1$ and $\mathrm{R} 1_{\text {free }}$ values of 0.17 and 0.22 respectively. The fact that these R-factors are relatively higher then those typically obtained with small molecules, is attributed to the unavoidable beam damage in our micron-sized crystals. Indeed, due to such irradiation, the exposure time had to be limited to 1 to $2 \mathrm{~s} /$ frame, with the result of a resolution of the X-ray data not better than $1.3 \AA$. Such resolution is lower than the one commonly obtained in the data collection on large crystals of small molecules.

The compatibility of the intensity values obtained on a given crystal was checked by re-refinement of the structure against the data collected on the other crystals. In order to do this, all 14 datasets collected on the selected A-amylose crystals were merged into two independent groups (7 original datasets per group) and the structure was re-refined against each of the two resulting datasets. The average discrepancy in the corresponding final atomic positions between these two groups was $0.03 \AA$. The highest deviation of $0.156 \AA$ was found for a primary hydroxyl group. These values reasonably match the e.s.d. of the atomic coordinates obtained after the refinement of the A-amylose structure against the whole diffraction dataset. 


\section{Results}

\section{Structure description}

As outlined in Table 1, the structure was refined in the monoclinic space group B2, with unit cell parameters $a=20.83(6) \AA, b=11.45(4) \AA, c$ (chain axis and monoclinic axis) = $10.58(3) \AA$ and $\gamma=122.0(2)^{\circ}$. In view of these parameters, the structure of A-amylose is based on the repeat of a maltotriosyl residue, and there are 4 such residues per unit cell. The labeling of the atoms along one of the amylose chain is shown in Figure 3, whereas the atomic final coordinates are presented in Table 2. The values of the bond lengths and angles are tabulated in the Supporting Information section. Each of these values falls in the range of those defined for polysaccharides containing pyranose rings. ${ }^{25}$ The main conformational angles defining the chain geometry are listed in Table 3. For reference, we also have listed In Table 3, the conformational parameters of the earlier A-amylose structure derived from fiber and electron diffraction analysis. ${ }^{10}$ A comparison of the present structure with the earlier one, indicates that the gross features of both structures are similar, but that they differ substantially in their finer details.

In agreement with the earlier structure, our A-amylose structure also consists of intertwined 6-fold left-handed parallel double helices, packed in a parallel fashion and tightly nested into one another. Each double helix is centered on the two-fold axis of the unit cell and the hydroxymethyl groups of each glucosyl residue adopt the $g g$ conformation. ${ }^{26}$ In both structures, the torsion angles $\varphi$ and $\psi$ are not so different from one glucosyl residue to the next, with a range from 79 to $93^{\circ}$ for $\varphi$, and from -145 to $-153^{\circ}$ for $\psi$. In these two structures, the sets of $\varphi$ and $\psi$ values that define the linkage of contiguous glucosyl residues indicate that the corresponding conformations fall in an area of minimum energy in the conformational energy $\varphi / \psi$ map of maltodextrin. ${ }^{27,28}$ In addition, these values also indicate that such sets of conformational angles preclude the formation of intramolecular hydrogen bonds within contiguous glucosyl residues. ${ }^{29}$ In contrast with the conformational torsion angles $\varphi$ and $\psi$, 
which are in reasonable agreement between this structure and the earlier one, there is some difference in the bond angles $\tau$ : in the present structure, $\tau$ ranges from 111 to $114^{\circ}$, whereas in the earlier structure, one of $\tau$ value was listed at $120.5^{\circ}$, a value that can be considered as rather high for $\alpha$-linked oligosaccharides. ${ }^{29}$ Another main difference between the present structure and the previous one is the orientation of the amylose molecules within the unit cell. In the earlier structure, a "parallel-up" situation ${ }^{11}$ was proposed, indicating that the hemiacetal terminal moiety, the so-called reducing end, was oriented along the c-axis directionality of the unit cell. In the present case, a "parallel-down" packing is unambiguously observed, since the $\mathrm{z}$ coordinates of the $\mathrm{C} 5$ are higher than those of $\mathrm{O} 5$ in any given glucosyl moieties.

\section{Water content}

An electron density map of the independent maltotriosyl residue together with its hydration system is shown in Figure 4. This projection reveals without ambiguity the existence of two water molecules per maltotriosyl unit in the crystal structure of A-amylose, whereas, from density consideration, only one was proposed in the earlier structure. This new feature brings substantial difference, not only for the system of hydrogen bonds, which has to account for new possibilities, but also for a distortion of the helices and of their internal cavity. This feature is well illustrated in Figure 5, which presents the projections of two structures on the $(a, b)$ plane: $5 \mathrm{a}$ for the present structure and $5 \mathrm{~b}$ for the earlier one. In the latter, the projection of each double helix has nearly a hexagonal shape, with each projected glucosyl residue forming one side of the hexagon and also presenting a hexagonal central hydrophobic cavity, with a diameter of $3.5 \AA$. In such projection, which is that of a closepacked hexagonal arrangement, each double helix is in contact with six neighbors and the water molecules - seen as dots in Figure $5 b$ - occupy the center of the interstitial spaces left open in such close packing. In contrast with this earlier structure, in the present structure, the 
projection of the double helices (Figure 5a) is no longer hexagonal, but somewhat deformed, as if they had been compressed along the $b$ direction of the unit cell. This leaves an elliptical central cavity that presents a short dimension of $2.5 \AA$, and a longer one of $4 \AA$. This deformation is likely due to the presence of the pocket of the two water molecules that need to push their way in the close-packed arrangement of the amylose double helices. They do so by compressing the helices in one direction and by somewhat modifying the hexagonal closepacked arrangement and the connections between the double helices.

\section{Hydrogen bonding}

The hydrogen bonding parameters in the present structure of A-amylose crystal, together with those of the earlier structure are listed in Table 4. The values confirm that there is no intra-molecular hydrogen bond in these structures, but rather inter strands and interdouble-helical bonds. In the present structure, all the hydrogen bonds correspond to oxygenoxygen distances between $2.62 \AA$ and $2.91 \AA$. In the inter-double helix category, two of the distances, namely the $\mathrm{O} 3 \ldots \mathrm{O} 31^{\mathrm{d}}$ and the $\mathrm{O} 21 \ldots \mathrm{O} 21^{\mathrm{f}}$, that were too far in the earlier structure, fall now in the hydrogen bonding category and thus reinforced the crystal packing. In the present structure, all the oxygen atoms of the primary and secondary hydroxyl groups appear to be involved into some type of hydrogen bonding, which was not the case in the earlier structure. As opposed to the earlier structure, where two intra-cyclic oxygen atoms were involved in hydrogen bonds with the water molecule, here only one of these, namely the O52 is at a close enough distance of the oxygen atom of OW2 to form a bond. The presence of two water molecules instead of one leads to a number of new hydrogen bonds, either between one of the amylose molecules and water or between the two molecules of water themselves. In Figures 6 and 7, drawings represent two projections the network of hydrogen bonds that either connect the double helices together or the water molecules to the remaining of the structure. Figure 6 , which is an $a / c$ projection, highlights the nesting of the double 
helices and the presence of the pockets of two water molecules tightly hooked to one another through hydrogen bonds. The pockets themselves are hydrogen bonded to the adjacent double helices, but there is no interconnection between one pocket and the other. The $a / b$ projections in Figure 7 show the details of the hydrogen bonds in a direction perpendicular to the double helix axes. In addition to the $\mathrm{O} 21 \ldots \mathrm{O} 21^{\mathrm{f}}$, and the bifurcated $\mathrm{O} 3 \ldots \mathrm{O} 31^{\mathrm{d}}$, which are new in this structure, one also notices the two strings of hydrogen bonds incorporating one or the other or

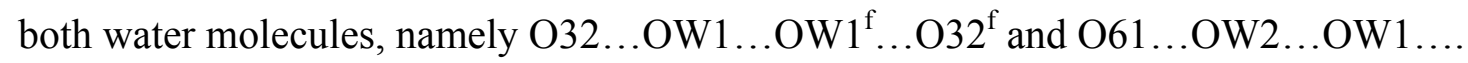
$O W 1^{\mathrm{f}} \ldots \mathrm{OW} 2^{\mathrm{f}} \ldots \mathrm{O} 61^{\mathrm{f}}$

\section{Discussion}

As aforementioned, the present resolution of the crystal structure of A-amylose modifies to some extent the existing knowledge on the ultrastructure of starch. Even if in their crystalline environment, the A-amylose helices appear less symmetrical than it was thought earlier. ${ }^{9,10}$ They are nevertheless more tightly bound by a better established network of hydrogen bonds, which leaves no hydroxyl or hydroxymethyl group un-connected. In addition, the presence of two molecules of water per maltotriosyl residues indicates that close to $7 \%$ of the weight of the crystal structure consist of water molecules as opposed to only $3.5 \%$ proposed in the earlier structure. Such low water content differentiates the weakly hydrated crystals of A-amylose from those of B-amylose, where a water content of up to $27 \%$ resulted from the structural analysis. ${ }^{30-32}$ This difference in hydration number explains why in A-amylose, the water molecules are located in discrete pockets that have no connection with one another, as opposed to B-amylose crystals where the water molecules are located between the double helices in wide channels occupying more than a quarter of the unit cell. When comparing the organization of the A- and B-amylose crystals, it is clear that the packing of the A-allomorph is significantly tighter than that of its B-counterpart, even if the structure of B-amylose, deduced only from fiber diffraction analysis is not known to high definition. ${ }^{30-32}$ 
Indeed, in A-amylose, there is a number of hydrogen bonds between adjacent double helices whereas in B-amylose, the connections between the double helices are mainly through hydrate water bridges. ${ }^{28-30}$ The crystal cohesion and therefore the thermal susceptibility of both allomorphs is thus expected to be substantially different. This is indeed the case since A-amylose crystals systematically melt by about $20^{\circ} \mathrm{C}$ above the B-specimens when subjected to the same hydrothermal treatment. ${ }^{33}$ In addition, the lower stability of B- versus A-sample toward heating is further enlightened when starch granules, such as those of potato, which present a B-crystal X-ray diagram, get irreversibly converted into the A-type after heating at low moisture for several hours. ${ }^{34}$ A similar conversion, but much faster, occurs when the hydrothermal treatment is directly applied to the crystalline fraction of potato starch recovered after partial acid hydrolysis of the granules. ${ }^{35}$

Quite interestingly, the preparation of A-amylose crystals requires conditions where the crystallization takes place in aqueous mixtures containing a small percentage - typically of the order of 10 to $15 \%$ - of a low polarity precipitant such as ethanol or acetone. ${ }^{8}$ Whereas the absence of precipitant leads to the formation of B-amylose crystals, ${ }^{8}$ its use at higher concentration, which intuitively should yield A-amylose crystals with a lower water content, invariably leads to V-amylose crystals, which are single-helical. ${ }^{8,36}$ Thus, the growth of the A-amylose crystals results from a tight balance between hydrophobic and hydrophilic interactions. Obviously, the dominant hydrophilic character is required to stabilize the amylose chains in double helices and not in single helices. On the other hand, the amount of hydrophobic precipitant required to obtain A-amylose crystals confines the size of the hydration domains to small water pockets, and not to large helical channels reported for Bamylose, when no hydrophobic precipitant is used to trigger the crystallization.

Another significant feature revealed in the present study is that the A-amylose crystal structure adopts a "parallel-down" organization, ${ }^{11}$ indicating that the non-reducing end of the amylose molecules is oriented toward the positive direction of the unit cell $c$-axis. This result 
is important since it allows correlating the unit cell matrix of A-amylose crystals with the biogenesis of these crystals within their starch environment. Indeed, it is known that starch synthases elongate starch molecules by adding D-glucopyranosyl units at the non-reducing ends of amylopectin, ${ }^{37-39}$ therefore also toward the positive direction of the $c$-axis of the Aamylose lattice. In a given amylopectin molecule, there is only one reducing end but multiple non-reducing ends are located at each dangling end of the short amylose fragments that branch out of amylopectin and form the A-amylose crystals. ${ }^{38,39}$ The fact that starch granules grow by apposition, since newly formed starch is deposited at or near the granule surface, ${ }^{37}$ would indicate that in the radial organization of the amylopectin chains, the reducing ends of these molecules should point toward the center of the granule, with the consequence of a radial organization of the positive direction of the $c$-axis, oriented from the granule center toward its periphery. So far, such geometry has not been proven due to the complex ultrastructure of starch granules that seem to consist of oblong crystalline blocklets having of the order of $100 \mathrm{~nm}$ in size and encompassing several amylopectin chains. ${ }^{38-40}$ At present, the directionality of the amylose crystals and therefore that of the amylopectin molecules within these blocklets are not known with certainty. Furthermore, the orientation of the individual blocklets with respect to one another is also a subject of debate. To answer such fundamental questions, there is thus a need to correlate the crystallographic geometry with the ultrastructure of native starch, the goal being to map out the directionality of the $c$-axis throughout the starch granules at the $100 \mathrm{~nm}$ level. At present, only X-ray microdiffraction maps at a $5 \mu \mathrm{m}$ scale have been recorded on individual starch granules. ${ }^{41-43}$

We believe that it is the first time that a recording of full X-ray datasets on micron-sized polymer crystals has been made. This study thus opens the way to determine with precision the three-dimensional structure of polymers. So far, the only accessible diffraction data from polymers crystals resulted from either X-ray fiber diagrams or single crystal electron diffraction diagrams. Whereas the data from the former were limited and 
difficult to deconvolute, those of the latter were important to yield lattice parameters and symmetry elements, but frequently failed to provide processible diffraction intensities, due to overlapping dynamic contributions that were proven hard to evaluate. With the current development of synchrotron microfocus beamlines, it now becomes possible to envisage the recording of reliable X-ray datasets on one polymer single crystal. This study has shown the benefit of this recent development for the resolution of a polymer crystal structure, using a conventional crystallography structure determination protocol. The present structure of Aamylose describes only one of the numerous allomorphs in which amylose is susceptible to crystallize as micron-sized single crystals. ${ }^{44,45}$ Many of these are in fact crystallosolvates, where amylose single helices are co-crystallized with guest molecules that are located either within the helical cavities and/or in between the helices. These easy-to-prepare crystalline complexes are quite important for the science of starch, since they allow not only the fractionation of starch, but also the slow release of the guests over a number of days or even months. Despite extremely rich electron diffraction diagrams, indicative of a high crystal perfection, these complexes have so far eluded any structural determination. The resolution of their structures, using the methods that have been presented here, would represent a substantial advance to understand and predict the numerous structural possibilities offered by amylose in vitro and therefore by starch inside native granules.

The present dataset was collected with an X-ray microbeam that had a diameter of 10-30 $\mu \mathrm{m}$. X-ray beams that are at least 10 times narrower are already available today on a routine basis for single crystal structure analysis. ${ }^{13,14}$ As already shown in protein crystallography, this will allow structure determination on even smaller crystal volumes of polymers. ${ }^{14}$ A potential target might be the structure of B-amylose. We also note that $100 \mathrm{~nm}$ and smaller beams start to become available. ${ }^{46}$ With such nanobeams, it will be possible to probe the local structure of starch blocklets in thin sections, to test their crystallinity and orientation and thus to transpose the data obtained with the in vitro model system investigated 
here to the starch granule itself and understand the relation existing between its biogenesis and its ultrastructure.

Acknowledgments. The authors thank C. Albenne and P-C. Escalier (LISBP) for preparing the fraction of synthetic amylose used in this study, as well as K. Mazeau (CERMAV) for his help with molecular graphics and Y. Nishiyama (CERMAV) for valuable discussions.

Supporting Information Available: List of bond lengths and angles. This information is available free of charge via the Internet at http://pub.acs.org. 


\section{Figure captions}

Figure 1. a: SEM image of A-amylose crystals prepared by recrystallization of synthetic amylose. b: One crystal glued to a borosilicate glass capillary tip.

Figure 2. One quadrant of a typical X-ray diffraction diagram of a crystal, as in Figure 1b, obtained in $1 \mathrm{~s}$ during a $2^{\circ}$ rotation. Insert: example of the intensity distribution across one of the diffraction spots (circled).

Figure 3. Labeling of the carbon and oxygen atoms together with the torsion angles $\varphi$ and $\psi$ and the bond angle $\tau$ along one of the strands of an A-amylose double helix.

Figure 4. Independent maltotriosyl residue and two hydration water molecules in $2 \mathrm{Fo}-\mathrm{Fc} 1 \sigma$ electron density map.

Figure 5. Projection on the $(a, b)$ plane of $\mathbf{a}$ : the present structure; $\mathbf{b}$ : earlier structure ${ }^{10}$ derived from a fiber and electron diffraction data. The dots represent the oxygen atoms of the water molecules.

Figure 6. Projection on the $(a, c)$ plane of the structure of A-amylose. The dots correspond to the oxygen atoms of the water molecules. Details of the hydrogen bonding are represented by dashed lines.

Figure 7. Hydrogen bonds of structure of A-amylose in the $(a, b)$ plane. a: general view; b: details of a. 


\section{References and Notes}

1. Tadokoro, T. In Structure of Crystalline Polymers; John Wiley and Sons: New-York, $1979 ;$ p 6.

2. Stout, G. H. and Jensen, L. H. In X-ray Structure Determination. A Practical Guide; Collier-Macmillan Ltd: London, 1968; p 161.

3. Geil P. H. In Polymer Single Crystals; John Wiley and Sons: New-York 1963.

4. Perez, S.; Chanzy, H. J. Electron Microsc. Technique 1989, 11, 280-285.

5. Starch granules contain a high percentage of high molecular weight amylopectin, a highly branched macromolecule whose clusters of short linear (amylose-like) branches intertwine into parallel-stranded double helices, which pack together into crystalline domains, responsible for the crystallinity of native starch. Depending on the parent plant species and the packing of the double helices, one distinguishes two different allomorphs, namely A- and B-starch.

6. Katz, J. R.; Van Italie, T. B. Z. Physik. Chem. (A) 1930, 150, 90-100.

7. (a) Wu, H-C. H.; Sarko, A. Carbohydr. Res. 1977, 54, C3-C6. (b) Wu, H-C. H.; Sarko, A. Carbohydr. Res. 1978, 54, 27-40.

8. Buléon, A.; Duprat, F.; Booy, F. P.; Chanzy, H. Carbohydr. Polym. 1984, 4, 161-173.

9. Imberty, A.; Chanzy, H.; Perez, S.; Buléon, A.; Tran, V. Macromolecules 1987, 20, 2634-2636.

10. Imberty, A.; Chanzy, H.; Perez, S.; Buléon, A.; Tran, V. J. Mol. Biol. 1988, 201, 365378.

11. The "parallel-up" and "parallel-down" situations are described according to the definition given in the following: French, A. D.; Holey, P. S. In Cellulose and Wood, Chemistry and Technology: Schuerch, C. Ed.: Wiley: New York, 1989; p 159.

12. Riekel, C. J. Rep. Prog. Phys. 2000, 63, 233-262. 
13. Moukhametzianov, R.; Burghammer, M.; Edwards, P.; Petitdemange, S.; Popov, D.; Fransen, M.; McMullan, G.; Schertler, G.; Riekel, C. Acta Cryst. D. 2008, 64, 158-166.

14. Volkringer, C; Popov, D.; Loiseau, T.; Guillou, N.; Ferey, G.; Haouas, M.; Taulelle, F.; Mellot-Draznieks, C.; Burghammer, M.; Riekel, C. Nat. Mater. 2007, 6, 760-764.

15. Popov, D.; Burghammer, M.; Buléon, A.; Montesanti, N.; Putaux, J-L.; Riekel, C. Macromolecules 2006, 39, 3704-3706.

16. Potocki de Montalk, G.; Remaud-Simeon, M.; Willemot, R.-M.; Planchot, V.; Monsan, P. J. Bacteriol. 1999, 181, 375-381.

17. Lengeler, B.; Schroer, C.G.; Benner, B.; Guenzler, T.F.; Kuhlmann, M.; Tuemmler, J.; Simionovici, A.S.; Drakopoulos, M.; Snigirev, A.; Snigireva, I. Nucl. Instrum. Methods Phys. Res., Sect. A 2001, 467-468, 944-950.

18. Riekel, C.; Burghammer, M.; Schertler, G. Curr. Opin. Struct. Biol. 2005, 15, 556-562.

19. Kabsch, W. in International Tables for Crystallography, Vol F: Crystallography of Biological Macromolecules, Rossmann, M. G.; Arnold, E eds., Kluwer Academic Publishers: Dordrecht, the Netherlands, 2001; p 730.

20. Egert, E.; Sheldrick, G. M. Acta Cryst. 1985, A41, 262-268.

21. Farrugia, L. J. J. Appl. Cryst. 1999, 32, 837-838.

22. Gagnaire, D.; Perez, S.; Tran, V. Carbohydr. Res. 1980, 78, 89-109.

23. Sheldrick, G. M. SHELX97, release 97-2, 1997, University of Gottingen, Germany.

24. Diederichs, K. ; Karplus, P. Nat. Struct. Biol. 1997, 4, 269-275.

25. Arnott, S.; Scott, W. E. J. Chem Soc. Perkin II. 1972, 324-335.

26. The conformation of the hydroxymethyl group is defined by two letters, the first referring to the torsion angle $\chi(\mathrm{O} 5-\mathrm{C} 5-\mathrm{C} 6-\mathrm{O} 6)$ and the second to the torsion angle $\chi^{\prime}$ (C4-C5-C6-O6). An ideal gg conformation would be defined as the set of two angles $-60^{\circ}$ and $60^{\circ}$.

27. Pangborn, W.; Langs, D.; Perez, S. Int. J. Biol. Macromol. 1985, 7, 363-369. 
28. Tran, V.; Buléon, A.; Imberty, A.; Pérez, S. Biopolymers 1989, 28, 679-690.

29. Tvaroska, I.; Bleha, T. Adv. Carbohydr. Res. 1989, 47, 45-123.

30. Wu, H-C. H.; Sarko, A. Carbohydr. Res. 1978, 61, 7-25.

31. Imberty, A.; Perez, S. Biopolymers 1988, 27, 1205-1221.

32. Takahashi, Y.; Kumano, T.; Nishikawa, S. Macromolecules 2004, 37, 6827-6832.

33. Whittam, M. A.; Noel, T. R.; Ring, S. G. Int. J. Biol. Macromol. 1990, 12, 359-362.

34. Vermeylen, R.; Derycke, V.; Delcour, J. A.; Goderis, B.; Reynaers, H.; Koch, M. H. Biomacromolecules 2006, 7, 1231-1238.

35. Le Bail, P.; Bizot, H.; Buléon, A. Carbohydr. Polym. 1993, 21, 99-104.

36. Brisson, J.; Winter, W. T.; Chanzy, H. Int. J. Biol. Macromol. 1991, 13, 31-39.

37. French, D. in Starch, Chemistry and Technology, Whistler, R. L.; BeMiller, J. N.; Paschall, E. F. eds., Academic Press: Orlando 1984; p 187.

38. Buléon, A.; Colonna, P.; Planchot, V.; Ball. S. Int. J. Biol. Macromol. 1998, 23, 85-112.

39. Myers, A. M.; Morell, M. K.; James, M. G.; Ball. S. Plant Physiol. 2000, 122, 989-997.

40. Gallant, D. J.; Bouchet, B.; Baldwin, P. M. Carbohydr. Polym. 1997, 32, 177-191.

41. Buléon, A.; Pontoire, B.; Riekel, C.; Chanzy, H.; Helbert, W.; Vuong, R. Macromolecules 1997, 30, 3952-3954.

42. Waigh, T. A.; Hopkinson, I.; Donald, A. M.; Butler, M. F.; Heidelbach, F.; Riekel, C. Macromolecules, 1997, 30, 3813-3820.

43. Chanzy, H.; Putaux J-L.; Dupeyre D.; Davies, R.; Burghammer, M.; Montanari, S.; Riekel, C. J. Struct. Biol. 2006, 154, 100-110.

44. Yamashita, Y.; Ryugo, J.; Monobe, K. J. Electron. Microsc. 1973, 22, 19-26.

45. Buléon, A.; Véronèse, G.; Putaux, J-L. Aust. J. Chem. 2007, 60, 706-718.

46. Schroer, C.G.; Kurapova, O.; Patommel, J.; Boye, P.; Feldkamp, J.; Lengeler, B.; Burghammer, M.; Riekel, C.; Vincze, L.; Van der Hart, A.; Küchler, M. Appl. Phys. Lett. 2005, 87, 124103-1-124103-3. 
Table 1. Experimental details

\section{Crystal data}

Chemical formula

Cell setting, space group

$a(\AA)$

$b(\AA)$

$c(\AA)$

$\gamma^{\circ}$

$V\left(\AA^{3}\right)$

$\mathrm{Z}$

Calculated density

Radiation type

$\lambda(\AA)$
$\mathrm{C}_{18} 0_{17} \mathrm{H}_{34}$

monoclinic, $B 2$

$20.83(6)$

$11.45(4)$

$10.58(3)$

$122.0(2)$

2140(11)

4

1.622

synchrotron X-ray

0.9465

\section{Data collection}

Diffractometer

Highest resolution $(\AA)$

Number of unique reflections

Number of free reflections

Total number of reflections measured

ESRF ID13

1.3

$987(155)^{1}$

98

Reflections $>2 \sigma(\mathrm{I})$

$5786(378)^{1}$

676

Temperature ( K)

100

Range of $h$

Range of $\mathrm{k}$

$-14=<\mathrm{h}=<16$

Range of 1

$-8=<\mathrm{k}=<8$

$-8=<1=<7$

Completeness \%

$98.6(91.8)^{1}$

$\mathrm{R}_{\mathrm{sym}}{ }^{2}$

$\mathrm{R}_{\text {sym }}$ (expected) ${ }^{3}$,

$0.193(0.712)^{1}$

$0.191(0.597)^{1}$

$\mathrm{R}_{\mathrm{mrgd}-\mathrm{F}}{ }^{2}$

$\mathrm{R}_{\text {meas }}{ }^{2}$

$0.137(0.677)^{1}$

$\mathrm{I} / \sigma(\mathrm{I})$

$0.202(0.813)^{1}$

$9.37(2.62)^{1}$

\section{Refinement}

Total number of the parameters refined

Total number of restraints

89

$\mathrm{R} 1^{4}$

0.1749

$\mathrm{R} 1_{\text {free }}{ }^{4}$

0.2216

\footnotetext{
${ }^{1}$ The numbers in parentheses correspond to the outer resolution shell 1.4/1.3 $\AA$

${ }^{2}$ Ref. 24

${ }^{3}$ Expected R-factor derived from $\sigma(\mathrm{I})$

${ }^{4} \mathrm{R} 1=\Sigma|| \mathrm{F}_{\mathrm{o}}|-| \mathrm{F}_{\mathrm{c}}|/ / \Sigma| \mathrm{F}_{\mathrm{o}} \mid$
} 
Table 2. Fractional coordinates and thermal parameters of independent atoms (e.s.d. values are given in parentheses).

\begin{tabular}{|c|c|c|c|c|}
\hline Atom & $\mathrm{x}$ & $\mathrm{y}$ & $\mathrm{Z}$ & $U_{i s o}, \AA^{2}$ \\
\hline O1 & $0.0995(14)$ & $0.272(3)$ & $0.673(3)$ & $0.124(10)$ \\
\hline $\mathrm{O} 2$ & $0.2542(16)$ & $0.413(3)$ & $0.626(3)$ & $0.129(10)$ \\
\hline $\mathrm{O} 3$ & $0.2940(13)$ & $0.304(3)$ & $0.838(3)$ & $0.108(9)$ \\
\hline O5 & $0.1216(15)$ & $0.381(3)$ & $0.867(3)$ & $0.131(10)$ \\
\hline O6 & $0.114(2)$ & $0.357(4)$ & $1.136(4)$ & $0.179(15)$ \\
\hline $\mathrm{C} 1$ & $0.1498(14)$ & $0.391(3)$ & $0.743(3)$ & $0.082(12)$ \\
\hline $\mathrm{C} 2$ & $0.2259(15)$ & $0.406(3)$ & $0.750(3)$ & $0.116(17)$ \\
\hline $\mathrm{C} 3$ & $0.2238(14)$ & $0.292(3)$ & $0.822(3)$ & $0.117(14)$ \\
\hline $\mathrm{C} 4$ & $0.1853(15)$ & $0.270(3)$ & $0.951(3)$ & $0.100(13)$ \\
\hline $\mathrm{C} 5$ & $0.1112(14)$ & $0.264(3)$ & $0.929(3)$ & $0.094(13)$ \\
\hline C6 & $0.069(2)$ & $0.247(4)$ & $1.053(4)$ & $0.17(2)$ \\
\hline $\mathrm{O} 11$ & $-0.0710(14)$ & $0.122(3)$ & $0.343(3)$ & $0.142(10)$ \\
\hline $\mathrm{O} 21$ & $0.0220(16)$ & $0.401(3)$ & $0.299(3)$ & $0.154(11)$ \\
\hline $\mathrm{O} 31$ & $0.1355(18)$ & $0.473(4)$ & $0.489(4)$ & $0.25(2)$ \\
\hline O51 & $-0.0884(13)$ & $0.168(2)$ & $0.553(3)$ & $0.111(10)$ \\
\hline O61 & $-0.070(2)$ & $0.183(4)$ & $0.811(4)$ & $0.184(14)$ \\
\hline $\mathrm{C} 11$ & $-0.0718(15)$ & $0.218(2)$ & $0.427(3)$ & $0.113(14)$ \\
\hline $\mathrm{C} 21$ & $0.0060(15)$ & $0.3470(17)$ & $0.421(4)$ & $0.20(3)$ \\
\hline C31 & $0.0692(16)$ & $0.338(4)$ & $0.480(4)$ & $0.159(18)$ \\
\hline $\mathrm{C} 41$ & $0.0437(14)$ & $0.285(4)$ & $0.616(4)$ & $0.14(2)$ \\
\hline C51 & $-0.0328(14)$ & $0.148(3)$ & $0.608(4)$ & $0.135(17)$ \\
\hline C61 & $-0.0625(18)$ & $0.086(3)$ & $0.739(4)$ & $0.25(4)$ \\
\hline $\mathrm{O} 12$ & $-0.1670(15)$ & $-0.142(2)$ & 0.0000 & $0.126(10)$ \\
\hline $\mathrm{O} 22$ & $-0.2071(16)$ & $0.047(3)$ & $-0.041(3)$ & $0.137(11)$ \\
\hline $\mathrm{O} 32$ & $-0.1354(13)$ & $0.223(2)$ & $0.167(3)$ & $0.099(9)$ \\
\hline $\mathrm{O} 52$ & $-0.2224(14)$ & $-0.195(2)$ & $0.198(3)$ & $0.112(9)$ \\
\hline O62 & $-0.2232(19)$ & $-0.183(3)$ & $0.464(4)$ & $0.149(12)$ \\
\hline $\mathrm{C} 12$ & $-0.224(2)$ & $-0.147(3)$ & $0.077(3)$ & $0.18(2)$ \\
\hline $\mathrm{C} 22$ & $-0.2154(17)$ & $-0.008(3)$ & $0.081(3)$ & $0.103(13)$ \\
\hline $\mathrm{C} 32$ & $-0.1441(17)$ & $0.095(2)$ & $0.156(3)$ & $0.092(12)$ \\
\hline $\mathrm{C} 42$ & $-0.1434(18)$ & $0.034(2)$ & $0.284(3)$ & $0.113(14)$ \\
\hline $\mathrm{C} 52$ & $-0.1557(18)$ & $-0.107(2)$ & $0.267(3)$ & $0.118(17)$ \\
\hline C62 & $-0.164(2)$ & $-0.176(4)$ & $0.396(4)$ & $0.15(2)$ \\
\hline OW1 & $-0.074(2)$ & $0.429(4)$ & $0.992(4)$ & $0.203(18)$ \\
\hline OW2 & $-0.121(4)$ & $0.350(6)$ & $0.750(6)$ & $0.25(2)$ \\
\hline
\end{tabular}


Table 3. Conformational parameters. The e.s.d. values for the present results are given in parentheses while the e.s.d. values for the results from Ref. 10 are unknown.

\begin{tabular}{|c|c|c|}
\hline Glucosidic bond parameters $\left(^{\circ}\right)$ & Present work & Previous fiber and powder data ${ }^{8}$ \\
\hline$\tau_{1}(\mathrm{C} 1-\mathrm{O} 1-\mathrm{C} 41)$ & 111(2) & 117.0 \\
\hline$\tau_{2}(\mathrm{C} 11-\mathrm{O} 11-\mathrm{C} 42)$ & $112(2)$ & 113.6 \\
\hline$\tau_{3}\left(\mathrm{C} 12-\mathrm{O} 12-\mathrm{C} 4^{\mathrm{a}}\right)$ & $114(2)$ & 120.5 \\
\hline \multicolumn{3}{|c|}{ Torsion angles about the glucosidic linkages $\left(^{\circ}\right)$} \\
\hline$\phi 1(\mathrm{O} 5-\mathrm{C} 1-\mathrm{O} 1-\mathrm{C} 41)$ & $87(3)$ & 91.8 \\
\hline$\psi 1(\mathrm{C} 1-\mathrm{O} 1-\mathrm{C} 41-\mathrm{C} 51)$ & $-146(3)$ & -153.2 \\
\hline$\phi 2(\mathrm{O} 52-\mathrm{C} 12-\mathrm{O} 12-\mathrm{C} 4 \mathrm{a})$ & $79(3)$ & 91.8 \\
\hline$\psi 2(\mathrm{C} 12-\mathrm{O} 12-\mathrm{C} 4 \mathrm{a}-\mathrm{C} 5 \mathrm{a})$ & $-153(2)$ & -151.3 \\
\hline$\phi 2(\mathrm{O} 51-\mathrm{C} 11-\mathrm{O} 11-\mathrm{C} 42)$ & $93(3)$ & 85.7 \\
\hline$\psi 3(\mathrm{C} 11-\mathrm{O} 11-\mathrm{C} 42-\mathrm{C} 52)$ & $-145(2)$ & -145.3 \\
\hline \multicolumn{3}{|c|}{ Torsion angles of the hydroxymethyl group $\left(^{\circ}\right)$} \\
\hline$\chi 1(\mathrm{O} 5-\mathrm{C} 5-\mathrm{C} 6-\mathrm{O} 6)$ & $-65(4)$ & -70.7 \\
\hline$\chi^{\prime} 1(\mathrm{C} 4-\mathrm{C} 5-\mathrm{C} 6-\mathrm{O} 6)$ & $60(4)$ & 49.5 \\
\hline$\chi^{2}(\mathrm{O} 52-\mathrm{C} 52-\mathrm{C} 62-\mathrm{O} 62)$ & $-65(4)$ & -64.4 \\
\hline$\chi^{\prime 2}(\mathrm{C} 42-\mathrm{C} 52-\mathrm{C} 62-\mathrm{O} 62)$ & $57(4)$ & 55.6 \\
\hline$\chi 3(\mathrm{O} 51-\mathrm{C} 51-\mathrm{C} 61-\mathrm{O} 61)$ & $-62(3)$ & -58.1 \\
\hline$\chi^{\prime 3}(\mathrm{C} 41-\mathrm{C} 51-\mathrm{C} 61-\mathrm{O} 61)$ & $58(3)$ & 61.9 \\
\hline
\end{tabular}


Table 4. Hydrogen bonding in A-amylose. The e.s.d. values for the present results are given in parentheses while the e.s.d. values for the results from Ref. 10 are unknown.

\begin{tabular}{|c|c|c|}
\hline \multirow[t]{2}{*}{ Bond } & \multirow{2}{*}{$\begin{array}{l}\text { Present work } \\
\text { d }(\AA)\end{array}$} & \multirow{2}{*}{$\begin{array}{l}\text { Previous fiber and powder } \\
\qquad \text { data }^{8} \\
\text { d }(\AA)\end{array}$} \\
\hline & & \\
\hline \multicolumn{3}{|c|}{ Inter-strand hydrogen bonds } \\
\hline $\mathrm{O} 2 \ldots \mathrm{O} 62^{\mathrm{a}}$ & $2.91(4)$ & 2.93 \\
\hline O6 ...O2 $1^{\mathrm{b}}$ & $2.81(5)$ & 2.75 \\
\hline $\mathrm{O} 61 \ldots \mathrm{O} 22^{\mathrm{b}}$ & $2.89(5)$ & 2.66 \\
\hline \multicolumn{3}{|c|}{ Inter-double-helix hydrogen bonds } \\
\hline $\mathrm{O} 2 \ldots \mathrm{O} 6^{\mathrm{c}}$ & $2.62(5)$ & 2.63 \\
\hline $\mathrm{O} 3 \ldots \mathrm{O} 31^{\mathrm{d}}$ & $2.70(4)$ & 3.08 \\
\hline $\mathrm{O} 3 \ldots \mathrm{O} 32^{\mathrm{e}}$ & $2.78(3)$ & 2.78 \\
\hline $\mathrm{O} 21 \ldots \mathrm{O} 21^{\mathrm{f}}$ & $2.86(6)$ & 3.53 \\
\hline $\mathrm{O} 22 \ldots \mathrm{O} 62^{\mathrm{g}}$ & 2.64(4) & 2.68 \\
\hline \multicolumn{3}{|c|}{ Hydrogen bonds with water molecules } \\
\hline $\mathrm{OW} 1 \ldots \mathrm{O} 32^{\mathrm{b}}$ & $2.73(5)$ & \\
\hline OW $1 \ldots O W 1^{\mathrm{f}}$ & $2.61(9)$ & \\
\hline OW1...OW2 & $2.72(7)$ & \\
\hline OW2...O61 & $2.72(7)$ & \\
\hline OW $2 \ldots O 52^{\mathrm{h}}$ & $2.82(7)$ & \\
\hline $\begin{array}{l}\mathrm{a}-\mathrm{x},-\mathrm{y}, \mathrm{z} \\
\mathrm{b} \\
\mathrm{x}, \mathrm{y}, \mathrm{z}+1 \\
\mathrm{c}-\mathrm{x}+1 / 2,-\mathrm{y}+1, \mathrm{z}-1 / 2 \\
\mathrm{~d}-\mathrm{x}+1 / 2,-\mathrm{y}+1, \mathrm{z}+1 / 2 \\
\mathrm{e} \\
\mathrm{x}+1 / 2, \mathrm{y}, \mathrm{z}+1 / 2 \\
\mathrm{f}-\mathrm{x},-\mathrm{y}+1, \mathrm{z} \\
\mathrm{g}-\mathrm{x}-1 / 2,-\mathrm{y}, \mathrm{z}-1 / 2 \\
\mathrm{~h}-\mathrm{x}-1 / 2,-\mathrm{y}, \mathrm{z}+1 / 2\end{array}$ & & \\
\hline
\end{tabular}




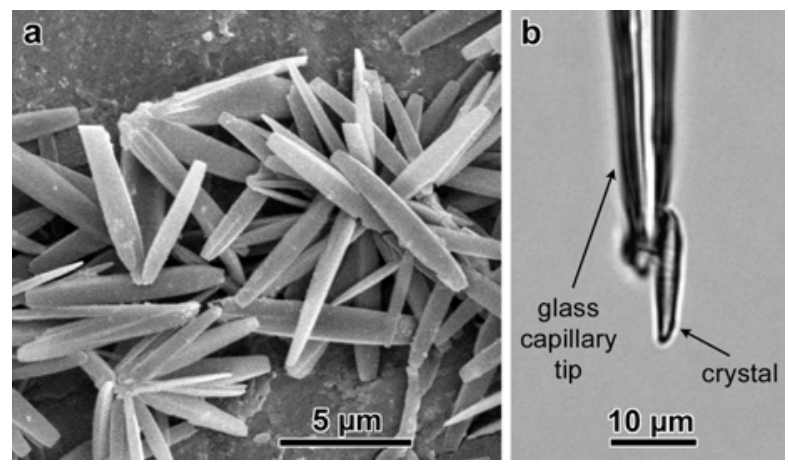

Figure 1 


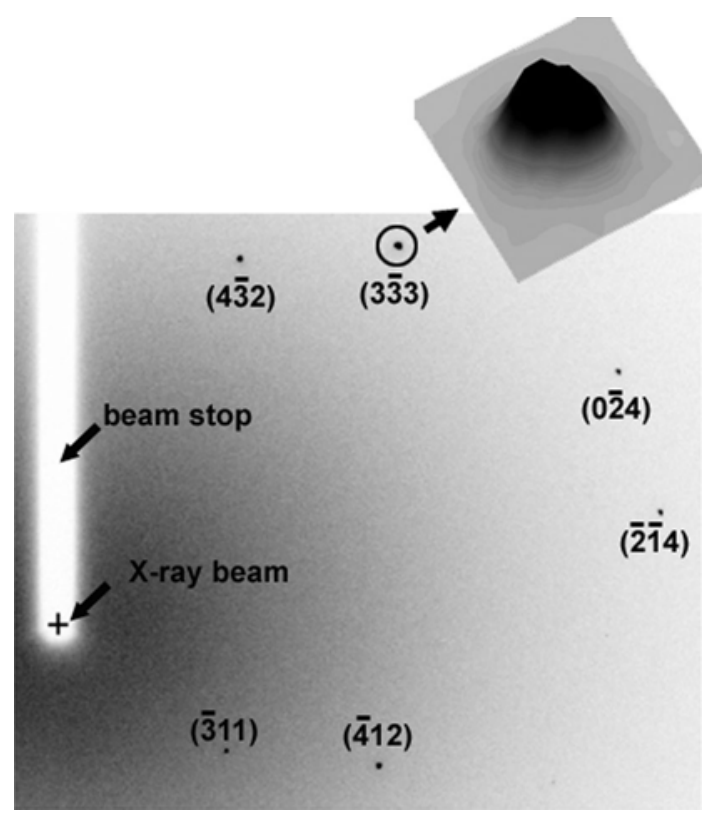

Figure 2 


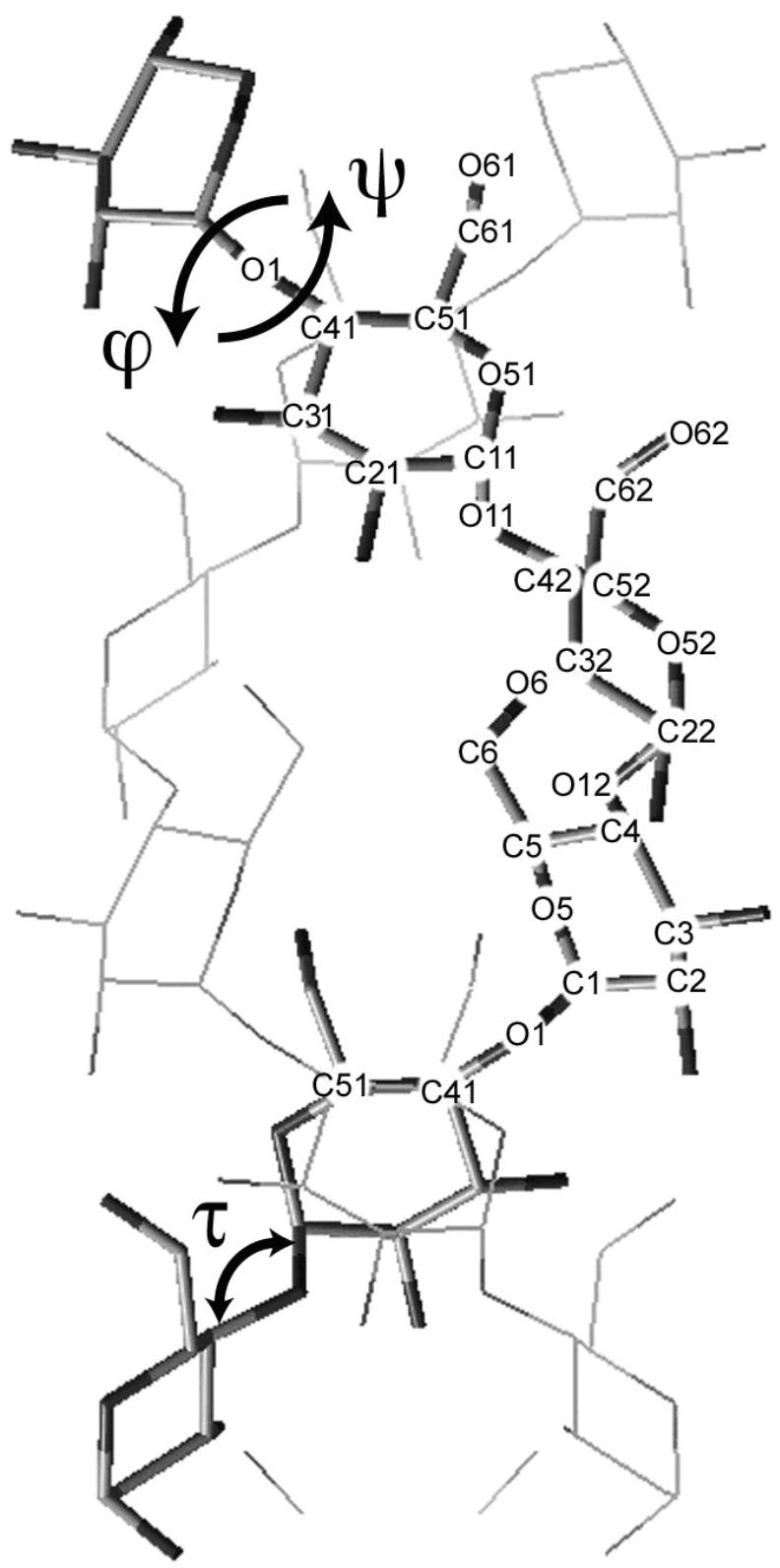

Figure 3 


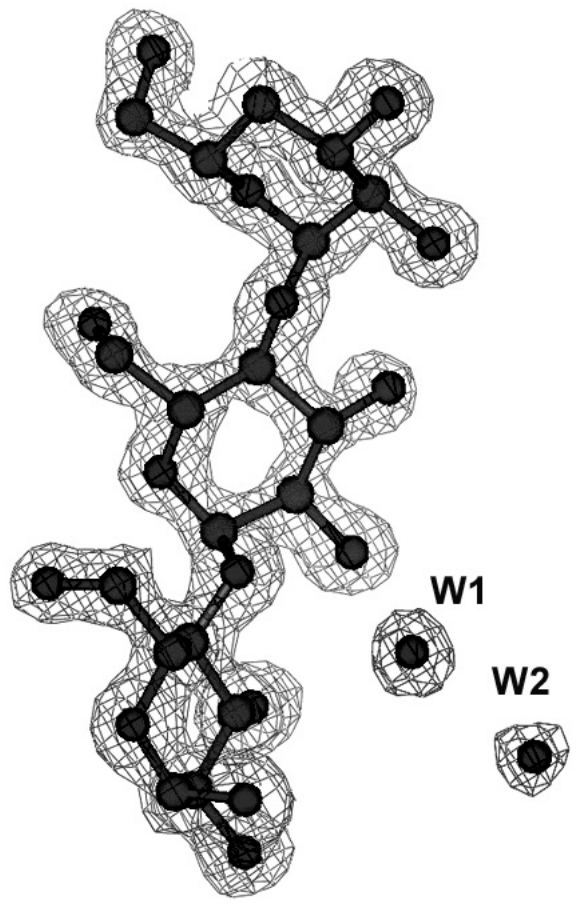

Figure 4 

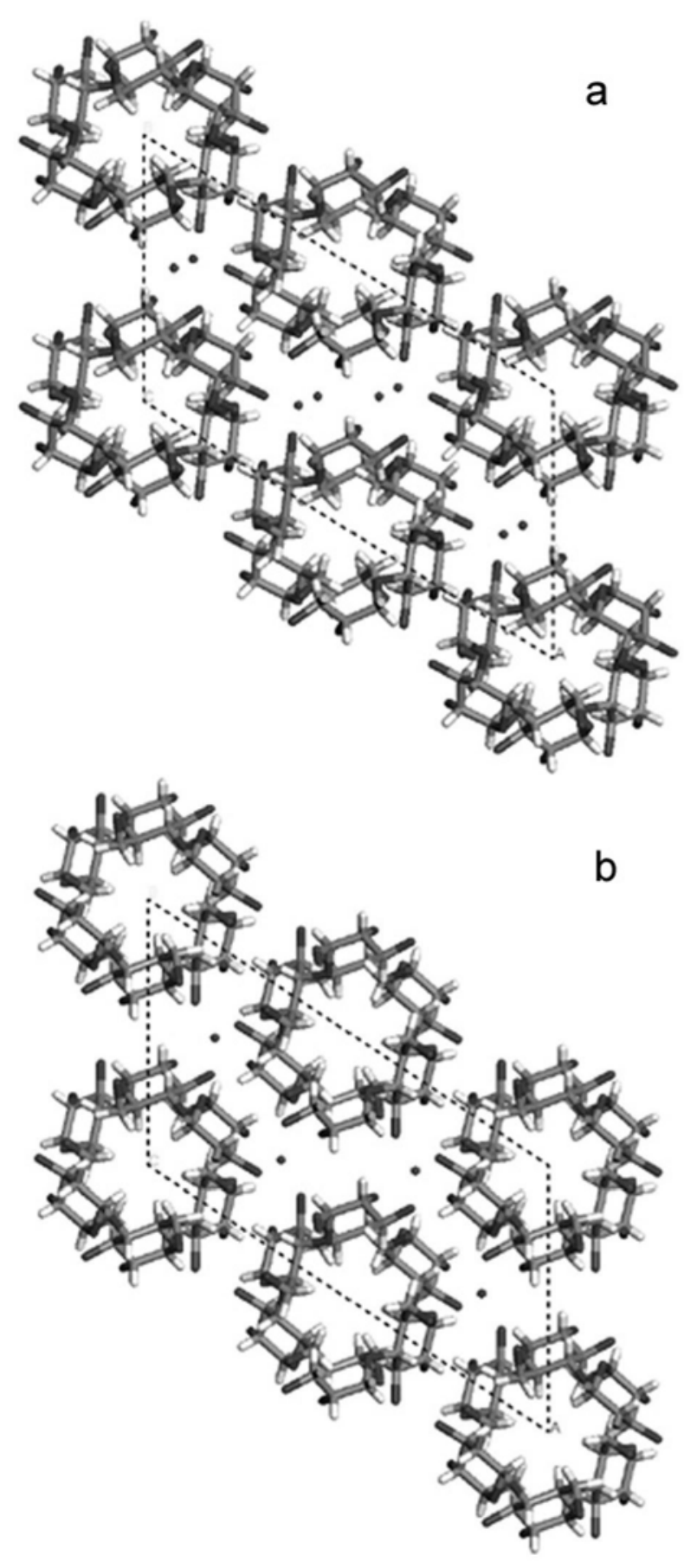

Figure 5 


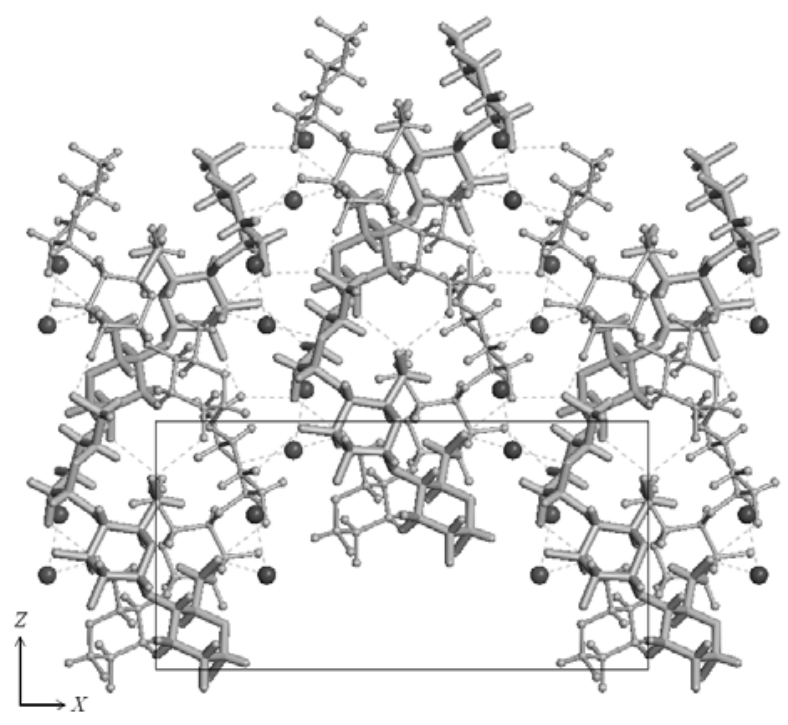

Figure 6 


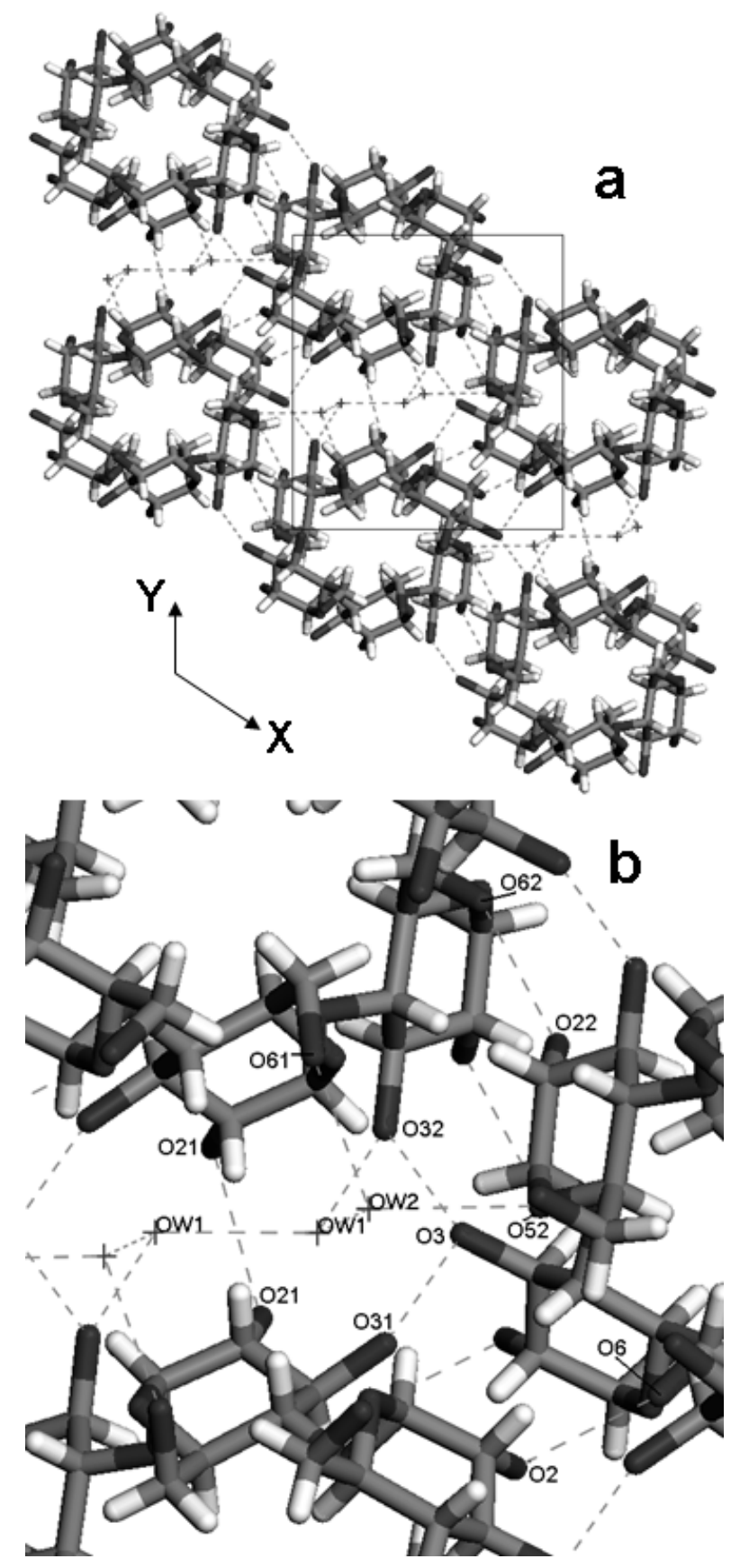

Figure 7 


\section{For Table of Contents use only.}

Crystal Structure of A-amylose: a Revisit from Synchrotron Microdiffraction Analysis of Single Crystals

D. Popov, A. Buléon, M. Burghammer, H. Chanzy, N. Montesanti, J-L. Putaux, G. Potocki-Véronèse, C. Riekel

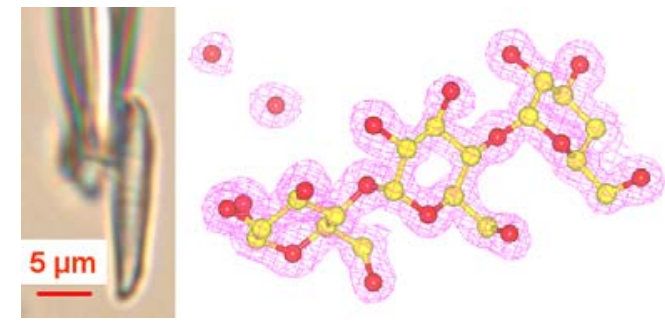

